\title{
Decision-Making Process for the Place of Death of Elderly Patients with Advanced Cancer and Their Families
}

\author{
Yoko Minamiguchi' ${ }^{\circledR}$, Kumi Suzuki² \\ ${ }^{1}$ Doctoral Program, Graduate School of Nursing, Osaka Medical College, Osaka, Japan \\ ${ }^{2}$ Faculty of Nursing, Osaka Medical College, Osaka, Japan \\ Email: taiyouko3@gmail.com
}

How to cite this paper: Minamiguchi, Y. and Suzuki, K. (2019) Decision-Making Process for the Place of Death of Elderly Patients with Advanced Cancer and Their Families. Open Journal of Nursing, 9, 12811305.

https://doi.org/10.4236/ojn.2019.912093

Received: November 25, 2019

Accepted: December 28, 2019

Published: December 31, 2019

Copyright $\odot 2019$ by author(s) and Scientific Research Publishing Inc. This work is licensed under the Creative Commons Attribution International License (CC BY 4.0).

http://creativecommons.org/licenses/by/4.0/

\begin{abstract}
Purpose: This study aims to understand how elderly patients with advanced cancer and their families make a decision for a place of death for the patient. Methods: Semi-structured interviews were conducted with 17 pairs of elderly patients and members of their family. The patients had finished anticancer treatment and made some decision about the preferred place of death. A modified grounded-theory approach was used for the data analysis. Results: Making a "tentative" decision for the place of death of the elderly patients is a process with the core category [carefully choosing the final place for self-fulfillment]. The patients were "conducting a comprehensive review of the place of death" and "embracing the wishes for a way of life without difficulty". Involving the family in making a "tentative" decision about the place of death of the elderly patients is the process with the core category [realizing the wish of patients in the terminal condition for the way for death]. The families were "examining the place of death from different aspects" and "respecting the patient's intention as far as possible". Conclusions: When the patients [carefully choosing the final place for self-fulfillment], it was important to reconcile their wishes with the burden on the families. When the families were trying to [realize the wish of patients in the terminal condition for the way for dying], it was important to balance the respect for the patient intentions and homecare they can provide for the patient. For the patients and their families, it is essential to mutually understand the intentions and wishes of the other party in decision making about the place of death.
\end{abstract}

\section{Keywords}

Advanced Cancer, Elderly Patients, Place of Death, Family, Decision Making 


\section{Introduction}

With the increasing number of elderly patients with cancer dying in Japan [1], the older the patient the more advanced the cancer staging becomes [2], and there are many elderly who are diagnosed with advanced cancer. Previously, it was possible for cancer patients to be hospitalized in hospitals for acute cases and receive treatment till the end-of-life even after there was no effective anticancer treatment. However, as functional differentiation among hospitals is increasing in Japan [3], it is difficult for patients to receive treatment in such acute hospitals till the end of life, and it is an urgent issue to consider where elderly patients with advanced cancer can spend their final days of life.

Dying at a preferred place is very important for cancer patients to maintain their own preferred way of life till the end because it affects the quality of life (QOL) of patients and alleviates the depression and sorrow for the bereaved family [4] [5]. Further, to make it possible for patients to die at a preferred place, it is necessary to make decisions about the place of death in advance because it has been reported that the disease conditions of cancer patients in the terminal stage tend to worsen suddenly [6], and that $42.5 \%$ of elderly patients required decisions about treatment in the final days of life and $70 \%$ of such patients lacked the capacity to make such a decision [7]. For these reasons, it is difficult for patients to decide on the preferred place of death after their condition has worsened, and the families are under stress to decide on the final place in a short period of time [8]. Therefore, it is important to decide the place of death in advance to make patient and family realize how they wish matters to be settled when anticancer treatment is no longer effective. Further, even if cancer patients have decided on a preferred place of death in advance, there will be cases where the place has to be changed due to painful symptoms, decreased physical functioning, and family caregiving ability [9]. This suggests that if the first decision is satisfactory for both the patients and their families, they will be able to more easily change the place where death is assumed to take place when the situation makes the patients wish to change the preferred place. For this reason, it is indispensable to make a "tentative" decision about the place of death when anticancer treatment has ceased to be effective so that patients can maintain their QOL and die in their preferred way.

In decision making about the place of death of cancer patients, the thoughts of the families as well as the patients are important because it affects the daily life of families [10]. In addition, since the thoughts of patients in the decision making are influenced by concerns of their family [11], it is important to understand how families are involved in the decision making, to enable the elderly patients to spend their final days at the preferred place. Previous studies have reported the experience of terminal cancer patients and families in decision making about the place of death [12], the decision-making process of terminal cancer patients and families [13], and identified 17 factors related to the place selection [14]. However, we have located no studies that clearly and in detail showed how el- 
derly patients with advanced cancer and their family members make decisions about the place of death before and after the end of anticancer treatment. Further, the "decision in the transition to the place of death" is reported to be the most important issue in cancer nursing research in Japan [15]. Therefore, we believe that if we have a better understanding of how elderly patients with advanced cancer and their family members make the "tentative" decision about the place of death, it will become possible to understand what kind of decision support is of assistance and how this is to be provided for such patients, and contribute to improving the quality of cancer nursing practices.

This study aims to understand how elderly patients with advanced cancer and their families make a "tentative" decision about a place of death for the patient.

\section{Methods}

\subsection{Definitions of Terms}

1) Decision making about the place of death: The best choice according to circumstances of the cancer patients among different options for a place of death, resulting from a careful evaluation of the wishes of these patients and the burden on the family, as well as through open discussions with other persons concerned [16].

2) Family: Regardless of marriage or blood relationship, person(s) who are mainly involved in patient care and decision making with mutual awareness as a family member.

\subsection{Study Design}

This study employed the exploratory qualitative descriptive design to search for factors due to the necessity to construct a theory based on data to understand how the elderly patients with advanced cancer and their families make decisions about a place of death for the patient.

\subsection{Participants}

Data were collected at a designated cancer care hospital, a home care clinic, and a hospice in the Kansai region in Japan. Inclusion criteria were 1) patients with advanced cancer over the age of $65(\geq 65)$ and their family, 2) patients who had finished anticancer treatments with the diagnosis that no radical cure could be expected, and had made some decision about the place of death, 3) patients who were able to communicate verbally and had no problems in cognitive functions that could affect communication, and 4) patients of whom the chief physician and nurse in charge had decided that the patients would be able to respond during 30 to 60 minute interviews. Exclusion criteria were 1) patients whose physical conditions were not stable, and 2) patients who were not mentally fit, harbored strong feelings of anxiety, or were not convinced of the disease condition. We requested the chief physician and nurse in charge to introduce us potential participants from among inpatients, outpatients, and patients in-home care to 
alleviate symptoms. We explained the purpose of the study in writing to the introduced potential participants and included those who expressed consent to participate in the study.

\subsection{Data Collection}

1) Survey period: August of 2018 to August of 2019

2) Data collection methods: We collected data through semi-structured interviews using an interview guide, and interviewed the patients and their families separately instead of interviewing them together to ensure that they would express their own ideas and thoughts straightforwardly: we first interviewed the patients who were the subjects to make the decisions about a place of death, and then the family member. Questions put to the patients are as follows: 1) Where do you wish to spend your final days of life, how do you wish to spend the days, and why? 2) How did you decide where to spend the time till the end of life? and 3) How did you decide on the treatments received so far and the discontinuation of further treatment? Questions to the family members are: 1) Where do you wish the patient, a member of your family, to spend he final days of life, how do you wish this relative to spend the days, and why? 2) How were you involved in the decision on where to spend the time till the end of life? and 3) How were you involved in the decision on the treatments received so far and the discontinuation of treatment? The number of interviews was once or twice per participant, and the length of an interview was about 30 to 60 minutes in consideration of the physical and psychological burden on the participants. The interviews used locations where the privacy of the participants could be protected. With the permission of the participants, the interviews were recorded on an electronic audio recording device, and transcribed. The demographic data of the participants were collected from the medical and nursing records with the permission of the participants.

\subsection{Data Analysis}

The data were analyzed using a modified grounded-theory approach (M-GTA) developed by Kinoshita (2003) [17]. Kinoshita modified the grounded-theory approach (GTA) proposed by Glaser and Strauss in the 1960s to an original coding method, taking advantage of the basic characteristics of the GTA. With the M-GTA the focus is on the participants when interpreting the data without splitting the data into segments. By generating a concept directly from the interpretation of the data, analysis is performed paying close attention to the data, and an original theory is generated. The M-GTA is suitable for research related to social interactions in which people interact directly and when the phenomenon that is subject to the analysis has a process-like character. We find the M-GTA suitable in this study because the decision making of patients with advanced cancer and their families about the place of death is a complex process and involves phenomena including interactions among participants, their fami- 
lies, and medical professionals.

The analysis was performed as follows. 1) A transcript was created from the recorded interview data. 2) Subjects that were the focus of the analysis were determined as "patients who had finished anticancer treatment and had made a 'tentative' decision about the place of death", and the topic of the analysis was "the process to make a 'tentative' decision about the place of death after the discontinuation of anticancer treatment". 3) We selected one subject case with many statements related to the topic of the analysis, extracted parts relevant to the topic of the analysis, and generated concepts from the identified matters. 4) We created a worksheet for each concept, and noted the name of the concept, its definition, specific examples, and theoretical remarks on the worksheet. 5) From the second case onward, we proceeded with the analysis from the viewpoint of opposites and similarities in the comparisons. 6) After completion of the analysis of all subjects identified, we examined the relationship between the concepts, and created categories. 7) Based on this, we examined the relationship between the categories, and drew up a result diagram that explains the decision making process for the place of death. 8) Finally, we wrote the explanations of the result diagram together into one "narrative" using the concepts and categories as a story line.

For the family data, we determined focal subjects for the analysis as "family members of patients who had finished anticancer treatment and made a 'tentative' decision about the place of death", and the topic of the analysis as "the process involved for the patients in making a 'tentative' decision about the place of death after the discontinuation of anticancer treatment". We conducted the procedures in (3) to (8) described above. In (7), we compared the relationship between the categories obtained from the patient data with those from the family data, and drew a result diagram that includes the details of the decision making process for the place of death.

\subsection{Credibility of the Data Analysis}

This study is based on standards to ensure the credibility of the qualitative research relying on published standards [18]. We used the M-GTA, which has been established as a qualitative method of analysis and as it is widely used in Japan, to ensure the credibility. Further, we selected facilities where the researchers are familiar with the organizational culture, to make it easier to establish mutual trust relationships between researchers and participants. Also, we selected participants from three facilities to ensure a broad-based understanding, paying attention to avoiding biases in sex, age, and carcinoma types. The whole of the course of the study was supervised by several researchers familiar with cancer nursing and qualitative research. Further, the data collection period, the number of participating facilities and participants, particulars of the participants, the data collection method, and the interview durations are described in the paper to improve transferability. The study design, survey content, and anal- 
ysis methods are also described in the paper to improve dependability.

\subsection{Ethical Considerations}

This study was approved by the ethics review committees of Osaka Medical College and the institution where the study was conducted (Approval No. Nursing-91), as well as the ethics review committees of the participating facilities (No. 335, No. 2018-046). Where a facility had no ethics review committee, we conducted the study by obtaining permission from the director of the facility. The study purpose, details of cooperation requested, methods, protection of privacy, personal benefits and disadvantages arising from this study, voluntary participation, methods of withdrawal of consent and publication of the study results were detailed to the participants in writing. We also explained the way of storing and discarding the study data. Participants expressed consent to the participation in the study by attaching signatures to the informed consent form.

\section{Results}

\subsection{Demographics (Table 1)}

The participants were 17 pairs of elderly patients with advanced cancer over 65 years of age and members of their family (in total 34 persons). The patients had finished anticancer treatment and made some decision about the preferred place for death. The gender of patients: 6 males/11 females, and of family members: 6 males/11 females; the mean age of the patients: 77.9 years, and of the family members: 67.4 years. The treatment facilities at the time of the survey: for $7 \mathrm{pa}-$ tients at hospitals, 5 at hospices, and 5 at home (including home hospices). The "tentatively" decided place for death: for 7 patients at hospitals, 8 at hospices, and 2 at hospitals/hospices/home (including home hospices). The family member relationships: 8 spouses, 8 children, and 1 sister. The number of interviews: 1 - 2 times per participant, and the average interview length per participant: 30 minutes for patients and 38 minutes for the family members.

\subsection{Results of the Analysis}

The analysis yielded 21 concepts for the patients, and 20 for the family members. Details are described in the following sections, and Figure 1 and Figure 2 show the results of the analysis by patient and family member. Core categories are indicated with square brackets ([ ]), categories are with single quotation marks ('”), and concepts with angular brackets $(<>)$.

\subsection{Results of the Analysis}

\subsubsection{Results with the Patients}

\section{1) Story line}

Making a "tentative" decision about the place for death of the elderly patients with advanced cancer after the discontinuation of anticancer treatment is a process with the core category [carefully choosing the final place for self-fulfillment]. 


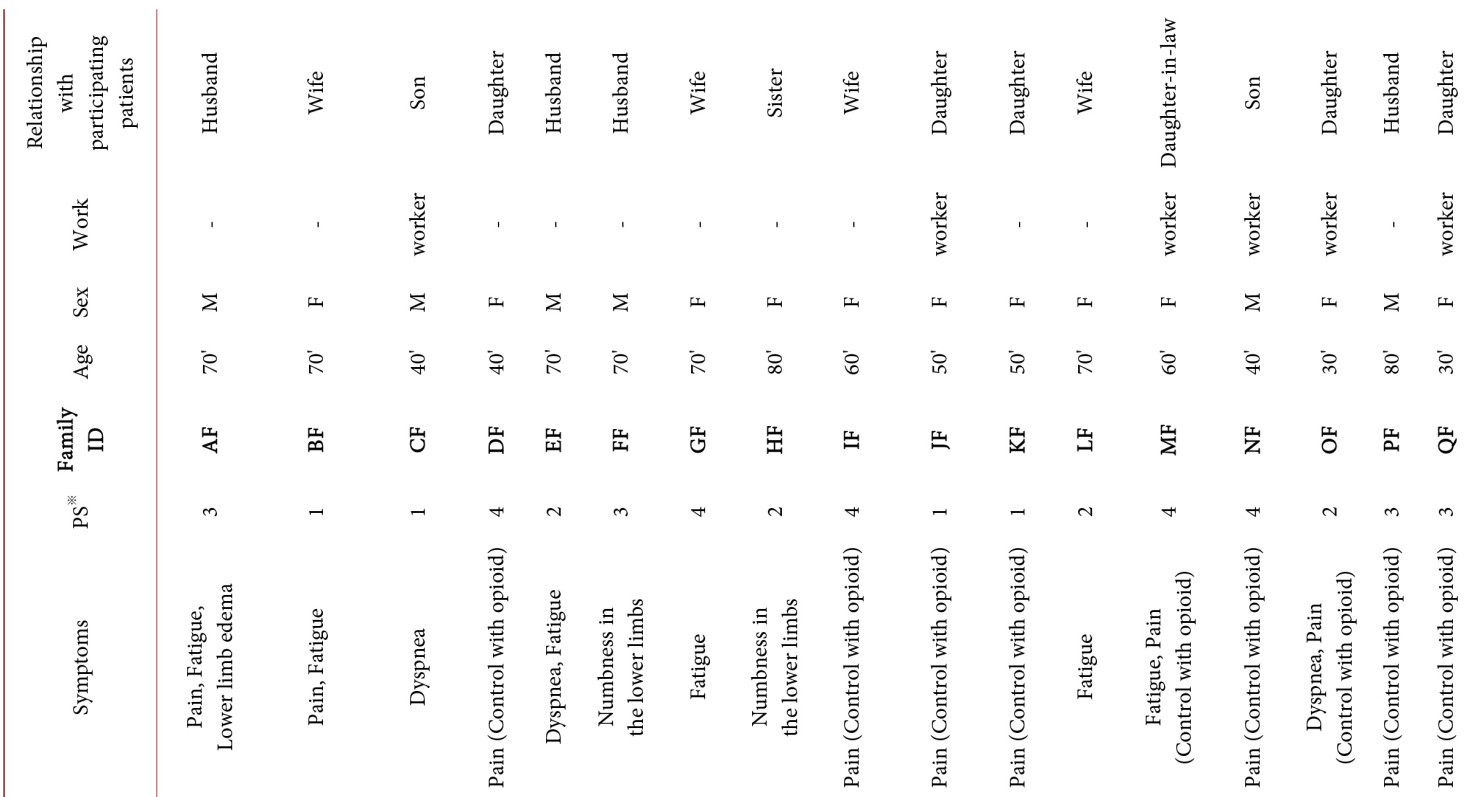

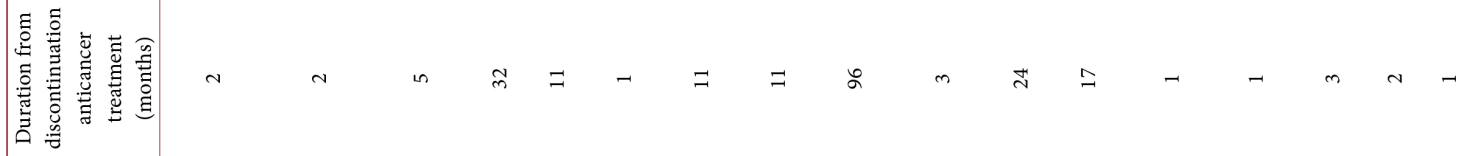

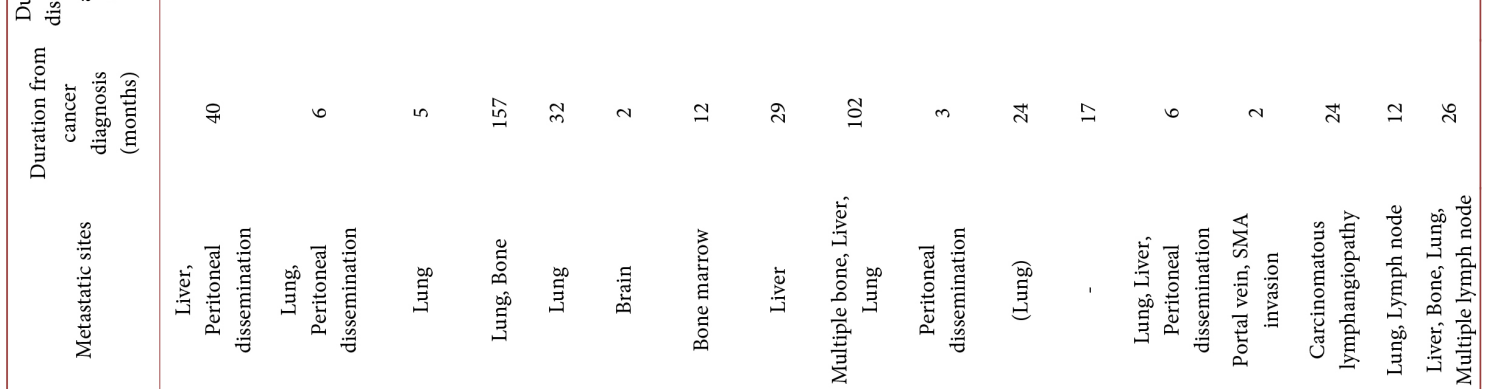

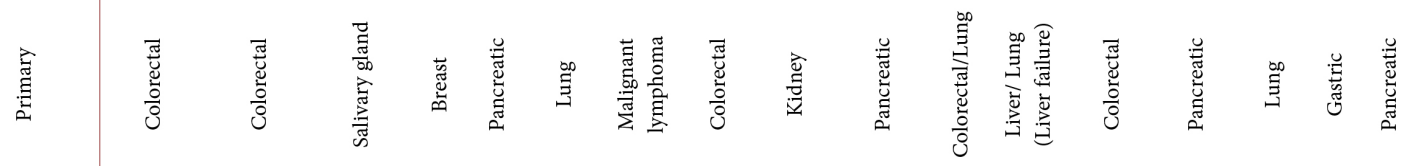

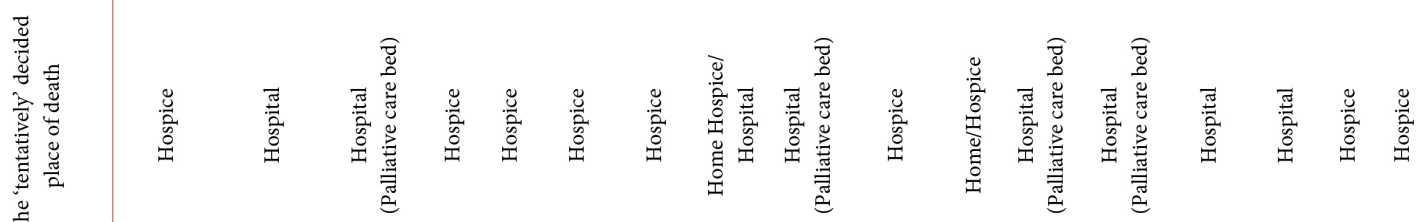

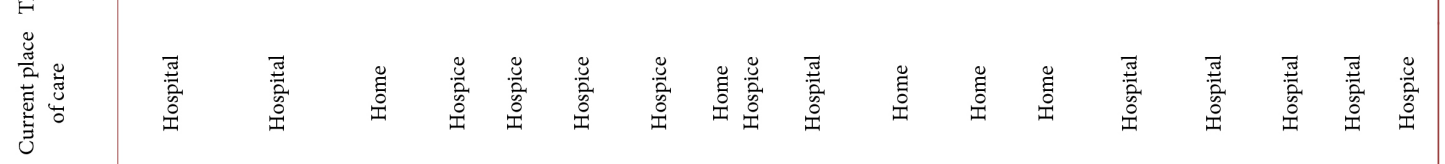

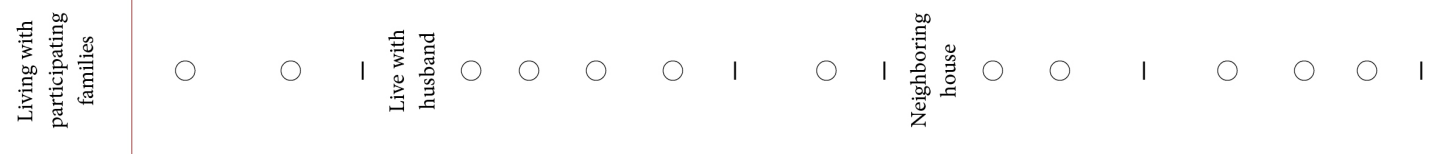
获山

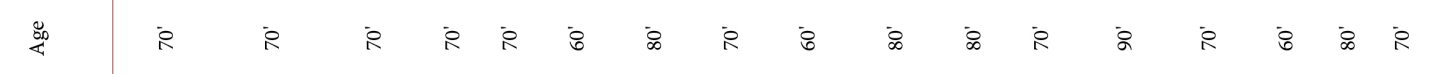

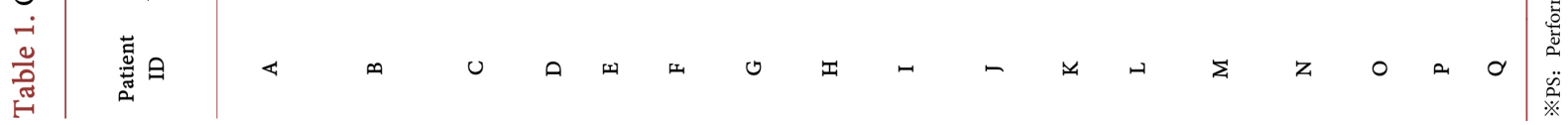




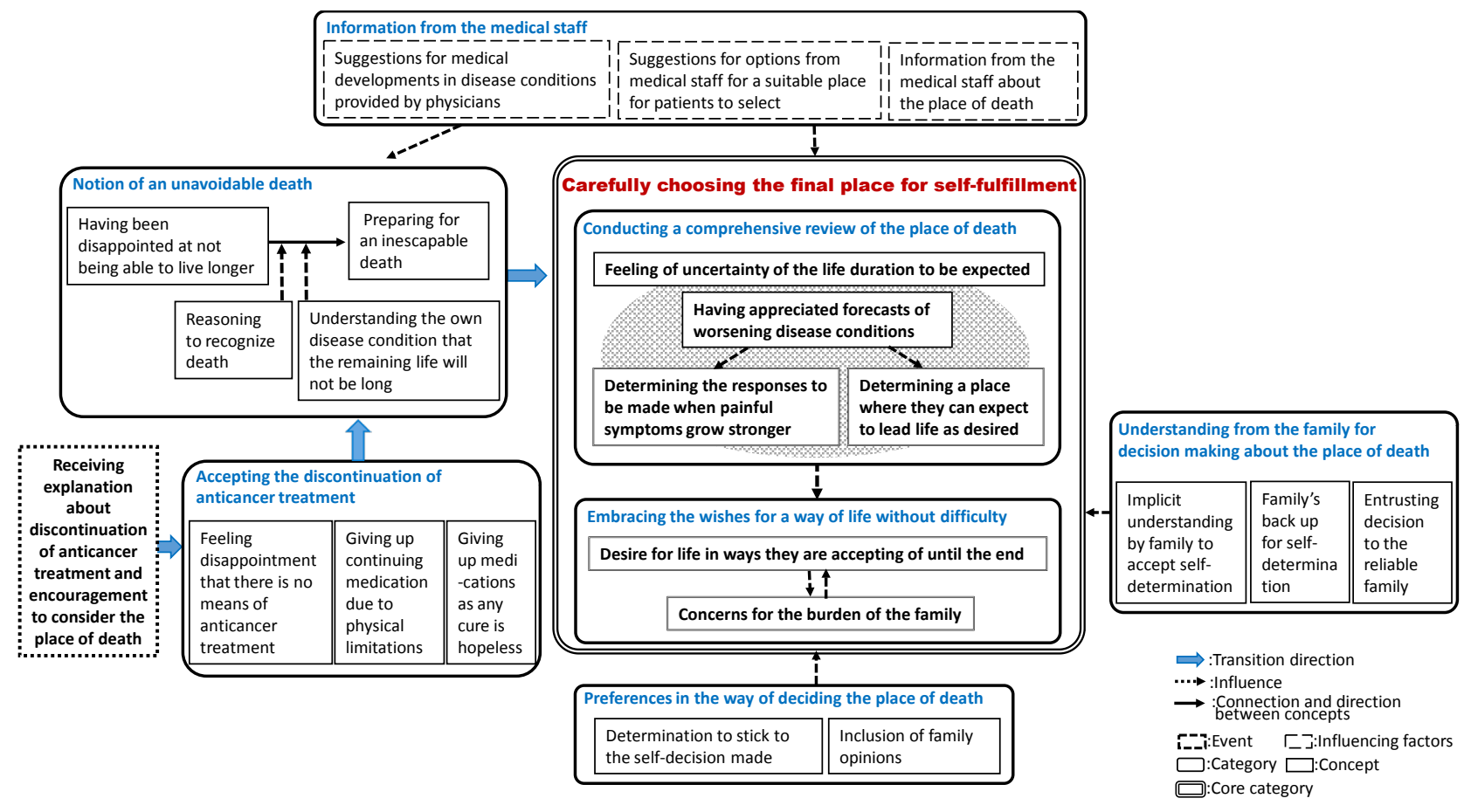

Figure 1. The result diagram about making a "tentative" decision for the place of death of the elderly patients with advanced cancer.

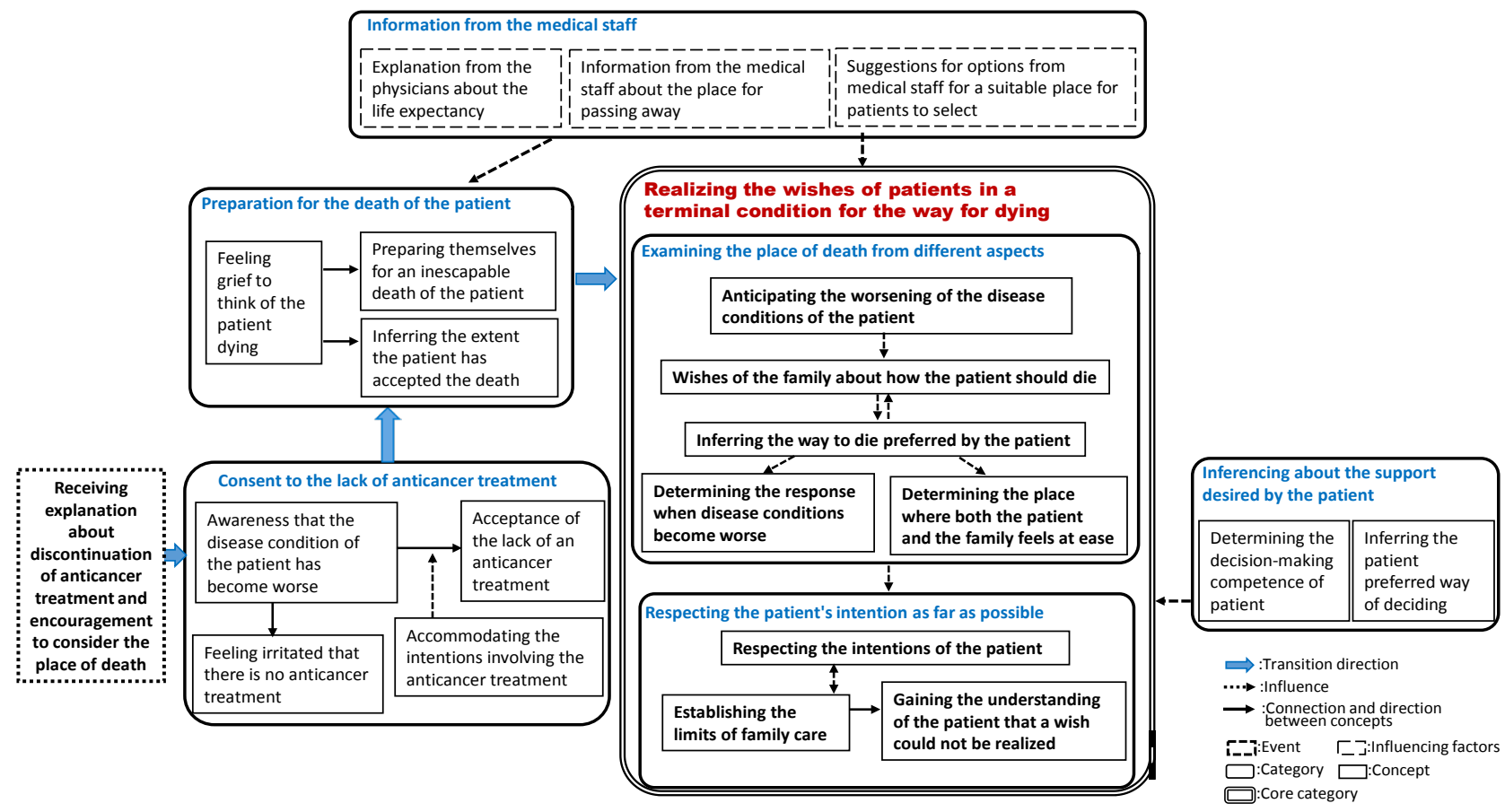

Figure 2. The result diagram about involvement of the patient family in making a "tentative" decision about the place of death of the elderly patients with advanced cancer.

Patients were "conducting a comprehensive review of the place of death", such as $<$ determining the responses to be made when painful symptoms grow stronger $>$ and $<$ determining a place where they can expect to lead life as desired $>$ by 
$<$ having appreciated forecasts of worsening disease conditions $>$ in a $<$ feeling of uncertainty of the life duration to be expected>, and "embracing the wishes for a way of life without difficulty" considering a $<$ desire for life in ways they are accepting of until the end > and the <concerns for the burden of the family>. [Carefully choosing the final place for self-fulfillment] was triggered by the "notion of an unavoidable death" illustrated by <preparing for an inescapable death $>$ by $<$ reasoning to recognize death $>$ and $<$ understanding the own disease condition that the remaining life will not be long $>$ while $<$ having been disappointed at not being able to live longer $>$ after "accepting the discontinuation of anticancer treatment" in the situation that was different for the different patients, expressed as $<$ feeling disappointment that there is no means of anticancer treatment $>$, < giving up continuing medication due to physical limitations $>$, and $<$ giving up medications as any cure is hopeless $>$. [Carefully choosing the final place for self-fulfillment] was conducted based on "preferences in the way of deciding the place of death" with "understanding from the family for the decision making about the place for death". Further, [carefully choosing the final place for self-fulfillment] was made easier by "information from the medical staff".

\section{2) Definition of core categories}

[Carefully choosing the final place for self-fulfillment] means to select a place where patients can live out the remaining period of life with dignity by living as they wish and agree is feasible for dying peacefully. This is a core category in the "tentative" decision-making process of the elderly patients with advanced cancer, and this core category includes this core category includes "conducting a comprehensive review of the place of death" and it is "embracing the wishes for a way of life without difficulty".

\section{3) The basis for the category concept}

The following sections describe the definitions of categories, and the concepts covered by the categories are shown with specific examples here. Events are indicated with double angled brackets $(<<>>)$, specific examples with Italics, supplementary explanations by a researcher with round brackets $(())$, and participant ID with (letters).

\section{A) "Accepting the discontinuation of anticancer treatment"}

"Accepting the discontinuation of anticancer treatment" expresses that patients have understood the continuation of the treatment as a burden on the body and consented to the discontinuation of the anticancer treatment which will mean that as a result death is bound to follow. This acceptance was conducted after $<<$ receiving explanation about the discontinuation of anticancer treatment and encouragement to consider the place of death $>>$ based on various considerations and depending on the patients.

<Feeling disappointment that there is no means of anticancer treatment>

"( When the doctor told me that there was no effective treatment), I felt a bit down. Nothing, any longer,... thinking that I cannot do anything. So I was curious about something where the Noble Prize was awarded. I asked the doctor if such treatment would be available for me (immunotherapy), but the doctor told 
me that it was not a cure-all. So, I accepted that I cannot be helped further. (B)"

<Giving up continuing medication due to physical limitations>

"I wish I could also continue treatment (medication following the radiation therapy), but I do not wish to live long under such a therapy. There I threw up (puked). It gave me a hard time. So, I asked the doctor to discontinue the treatment because of the vomiting, although there were other anticancer drugs. $(N)$ "

<Giving up medications as any cure is hopeless>

"Since I was told that I cannot have surgery because (the cancer) was spreading at the time of the examination, I was prepared for what would happen immediately after that. The doctor said that anticancer drugs do not work well. So my preference was to do nothing rather than suffering from anticancer drugs. I hope my present condition will last a little longer. And now I am still alive. (C)"

B) "Notion of an unavoidable death"

The "notion of an unavoidable death" means that patients themselves are prepared for the unavoidable death by an understanding of the own disease condition or after reasoning that their death is the life span remaining to them, while they still have an attachment to life. This is realized after "accepting the discontinuation of anticancer treatment". <Preparing for an inescapable death> is influenced by patients being able to understand the disease conditions through the explanation of physicians and having developed a reason for their own death.

$<$ Having been disappointed at not being able to live longer>

"(Because my first grandchild was born 7 months ago), I want to live even a little longer, but I do not know about the life span that I have. I cannot be helped. It is no use worrying about my life. (B)"

$<$ Reasoning in recognizing death $>$

"I have worked hard enough. So I think it would be acceptable for me (even if I die). I really worked hard. ( $K)^{\prime \prime}$

$<$ Understanding the own disease condition that the remaining life will not be long $>$

"With this disease, most people will die, and if I were really in the early stages, maybe I could undergo a different treatment and live longer. But my doctor told me that this disease (pancreatic cancer) advances rapidly and it is located in a position that is difficult to determine. (E)"

$<$ Preparing for an inescapable death>

"Well, I have to recognize mentally that I am going to die. I know I should not say that I cannot help doing anything, but I think that I have no choice but to face that it (death) is coming. (E)"

C) "Conducting a comprehensive review of the place of death"

"Conducting a comprehensive review of the place of death" means to consider if patients themselves or their family can cope with the situation when the disease condition worsens and if a specific place provides the medical care they desire, by preparing to accept the outcome of their own physical condition which is worsening and difficult to predict. 
$<$ Feeling of uncertainty of the life duration to be expected $>$

"I hope I will be taken care of at such a place (hospice) ill the last. I cannot know what will happen to me till then. ( $)$ "

< Having appreciated forecasts of worsening disease conditions>

"I know (my disease condition) myself. I cannot express it in numbers. But I cannot keep talking along, and I cannot keep singing because I cannot just keep singing. So, thinking about this kind of condition, summer will not come. (C)"

$<$ Determining the responses to be made when painful symptoms grow stronger $>$

"In the end if I do not do that (go to the hospice), I have nowhere to stay, I think. Well, what can I say, if the forecast is symptoms such as pain...) (A)"

$<$ Determining a place where they can expect to lead life as desired>

"For me because I have finished the treatment, I thought that it was in a hospital room that I would just finish my life. That was all I thought. But when I came here (to the hospice), there is not much difference (from the ward where I was treated). After all, I was thinking of, when I provided end-of-life care for my mother-in-law, many patients were in in one large room. Only the same types of patients. Having patients sleeping who are just proceeding towards the end. I imagined like this and thought it was too bad really. $(F)$ "

D) "Embracing the wishes for a way of life without difficulty"

"Embracing the wishes for a way of life without difficulty" means patients having a clear view of the place of death by considering that the care and mental burden on the family and the changes in the family life accompanied by the care will be reduced, while hoping to live out the remaining period of life with dignity by living as they wish and to die peacefully.

<Desire for life in ways they are accepting of until the end >

"I am doing various things, and I like cycling. But because my physical condition is like this (what I can do is limited), I hope I will be able do something at home, such as drawing. ( $O$ )"

$<$ Concerns for the burden of the family>

"If everyone is burdened, I would rather like to be hospitalized or look for a place like another facility... I do not want to show my suffering condition (to my family). No, never. I think my family will be sad (to see me coughing and struggling for air). ( $O$ )"

E) "Understanding from the family for the decision making about the place for death"

"Understanding from the family for decision making about the place for death" means that patients obtain acceptance from the family about deciding the place of death by themselves and entrusting the decision to the family. There were differences in how they obtained the acceptance for the different participating patients.

<Implicit understanding by family to accept self-determination>

"( When I told my family that I want to do this, my family) said nothing. My son knows $(N)$." 
<Family's back up for self-determination>

"I played the main part in the decision making. Yes, my family asked me what I wanted to do and I said that I wanted to stay at home as much as possible, but I would be taken care of at a hospital when I feel terrible. My family follows me; I don't know what to say but my opinion is respected. $(O)$ "

<Entrusting decision to the reliable family>

"I think it is okay because my daughter is responsible for or involved in (choosing the hospice). (D)"

F) "Preferences in the way of deciding the place of death"

"Preferences in the way of deciding the place for death" means the preference for how to decide the place of death, such as, to decide independently, or to decide with the family. Patients with a <determination to stick to the self-decision made> placed more emphasis on their desires for their way of life, while paying attention to the burden of their families. However, patients who are open to <inclusion of family opinions> placed more emphasis on the burden of the family, and reconciled in their desire for how to die.

$<$ Determination to stick to the self-decision made>

"My husband says that a nearby hospital is fine and that it is very convenient for him to visit me. (omitted) He does not say it has to be that way, but he recommends hospitals that are convenient for him to go to. I know that the hospital he recommends is close to my house, but I think I prefer it here (hospice). It is me who will stay there. (Omitted) So I do not want others to choose and tell me to stay there. If I do not understand something here, I cannot help it, but I do not like being told what to do. In my case. (E)"

$<$ Inclusion of family opinions >

"Yes, (I) hesitated to choose, but the children of my daughter are still first grade of elementary school and 3 years old. I told my daughter (it is in my daughter's house) that I want to die there, spending good days with my grandchildren. But my daughter asked me what to do if my condition suddenly changes (she was worried). I heard that a hospital will admit me if the condition suddenly changes, but (the hospital is) far from my daughter's house). (F)"

G) "Information from the medical staff"

"Information from the medical staff" means to be given explanations by medical staff about what may happen in the case of changes in the disease conditions, options for places of death, and medical and nursing care services available at home. These were the factors that are promoted when [carefully choosing the final place for self-fulfillment].

$<$ Suggestions for medical developments in disease conditions provided by physicians $>$

"Yesterday my doctor told me that I get mild medicines to relieve pain, but will have to use a kind of narcotic drug, is this right? I was told to take it when the pain gets worse. But then I do not know how my body will become, using drugs, how much I can endure. I cannot imagine what will happen, now. (B)"

$<$ Suggestions for options from medical staff for a suitable place for pa- 


\section{tients to select>}

"The doctor told me that the treatment is going to finish, and asked me if I wished to choose home or hospice. (F)"

<Information from the medical staff about the place of death>

" $(A$ nurse $)$ told me there is a hospice nearby. I think my family will want to visit me. I have heard that the husband of a friend spends his final days in such a place. $(P)^{\prime \prime}$

\subsubsection{Results with the Families}

\section{1) Story line}

Involving of the family in making a "tentative" decision about the place for death of the elderly patients with advanced cancer participating here, after the discontinuation of anticancer treatment, is the process with the core category [realizing the wish of patients in the terminal condition for the way for dying]. Family members were <anticipating the worsening of the disease conditions of the patient $>$, and <inferring the way to die preferred by the patient $>$ in light of the $<$ wishes of the family about how the patient should die $>$, and "examining the place for death from different aspects", such as $<$ determining the response when disease conditions become worse $>$ and $<$ determining the place where both the patient and the family feels at ease $>$. Further, family members were trying to "respecting the patient's intention as far as possible" by <establishing the limits of family care $>$ and $<$ gaining the understanding of the patient that a wish could not be realized $>$, while trying to $<$ respect the intention of the patient $>$.

[Realizing the wish of patients in the terminal condition for the way for dying] was triggered by the "preparation for the death of the patient" such as <preparing themselves for the inescapable death of the patient $>$, while $<$ inferring the extent the patient has accepted the death $>$ and $<$ feeling grief to think of the patient dying $>$ after having been made to "consent to the lack of anticancer treatment" such as an <acceptance of the lack of an anticancer treatment>, through <accommodating the intentions involving the anticancer treatment $>$ while $<$ feeling irritated that there is no anticancer treatment $>$ with the <awareness that the disease condition of the patient has become worse $>$. Involvement of the family in [realizing the wish of patients in the terminal condition for the way for dying] was based on an "inferencing about the support desired by the patient". Also, [realizing the wish of patients in the terminal condition for the way for dying] was promoted by the "information from the medical staff".

\section{2) Definition of core categories}

[Realizing the wish of patients in the terminal condition for the way for dying] means that family members attempt to realize the wishes of patients as far as possible while considering the limits of the care the family can provide and by inferring and examining the wishes of the patients for the place for death from the various information learned. This is a core category in the involvement of the family in the "tentative" decision-making process for the elderly patients with advanced cancer after the discontinuation of anticancer treatment, and this 
core category includes "examining the place for death from different aspects" and "respect the patient's intention as far as possible".

\section{3) The basis for the category concept}

The following sections describe the definitions of categories, and the concepts covered by the categories are shown with specific examples here. Events are indicated with double angled brackets $(<<>>)$, specific examples with Italics, supplementary explanations by a researcher with round brackets $(())$, and participant ID with (letters).

\section{A) "Consent to the lack of an anticancer treatment"}

"Consent to the lack of an anticancer treatment" means that family members become convinced that the patient had no other choice but to put an end to the treatment and that the discontinuation of the treatment would be beneficial to the patient. This is because the family members knew that the patient was suffering from the adverse effects and that the patient wished to discontinue the treatment, while feeling pressed as to if there are alternative treatments but when the family members knew there were no anticancer treatments available. The family members became convinced after [receiving the explanation about the discontinuation of anticancer treatment and encouragement to consider deciding the place for death]. Also, <Consent to the lack of an anticancer treatment> was made by <accommodating the intentions involving the anticancer treatment>.

$<$ Awareness that the disease condition of the patient has become worse $>$

"The problem is whether the patient is going to continue anticancer treatment or not. As the treatment advanced once, twice, three times, and a fourth time, different symptoms appeared and the patient seemed to feel run-down at home. Now I know that the treatment was not so effective. After all, the anticancer treatment became a burden on my mother. She seemed to think so from the beginning. (OF)"

$<$ Feeling irritated that there is no anticancer treatment>

"What to say..., for the last few months, since I knew that I could not do anything, I have been irritated thinking about whether there is any other way.... (Omitted) I am trying to find one, but I do not know if there is any other way. I searched for various treatments other than surgery through the internet, and found proton beam, heavy particle beam, radiation therapy, and other treatments. So I visited a hospital to consult about heavy particle beam therapy. (CF)"

<Accommodating the intentions involving the anticancer treatment>

"Our doctor said, "Your father, Mr. $K$ is lucid, and I think he is physically strong enough, so I would like him try it (treatment)". (Omitted). He said he thought that the patient (my father) was able to endure (the treatment), so he wanted my father to try it. At that time, I thought so too. As the doctor said so, I encouraged my father to try. But (my father) said "No" because it would be too hard for him. Then, the doctor suggested not to consider it because of the burden, unless the patient was willing to try. There is the burden, after all. When I heard the doctor said not to go ahead with it that is one option. I thought it 
stands to reason. $(K F)^{\prime \prime}$

\section{<Acceptance of the lack of an anticancer treatment>}

"Really, a short while after quitting (anticancer treatment), (my mother) was getting better. Yes, it happened. I said to my mother, "it was really good for you to stop the treatment. If you had not quit, you would be dead, mother." We talked about such things. $(D F)$ "

B) "Preparation for the death of the patient"

"Preparation for the death of the patient" means to keep the death of the patient in mind so that the family members will not be upset when the patient dies, while feeling sad thinking of the death of the patient. This is made after the "consent to the lack of an anticancer treatment" and for patient and family $<$ preparing themselves for an inescapable death of the patient $>$ and was prompted by an unambiguous explanation from the physicians about the life expectancy.

<Feeling grief to think of the patient dying>

"Because I have given my wife a lot of worries since we were young, this is the last chance to take care of her to return her kindness. I feel very sad. This is the opposite of how it should be. She is 10 years younger than me. If I were dying, that would be reasonable. But my wife, 10 years younger, is dying. (FF)"

<Preparing themselves for an inescapable death of the patient>

"I was told, 'another 3 to 6 months' left. The sixth month is coming soon. As it is November, the sixth month. May, June, July, August, September, October, and November. Just the sixth month now. His heart seems to be very weak. I heard some patients die during sleeping. So I myself need to be prepared to some extent $(B F)$."

$<$ Inferring the extent the patient has accepted the death>

"It was a few days after my mother was admitted here. The doctor told me that the life expectancy would be at most a month. No one told it (to my mother). She thinks she cannot live very long, and it seems she hopes for that in a sense. But I think she hopes for miracles to happen, because she sometimes expresses her feelings of uncertainty. I think she feels differently every day. $(M F)$ "

C) "Examining the place for death from different aspects"

"Examining the place for death from different aspects" means that the family members evaluate the place for death from different aspects considering the wishes of the family about the death of the patient, the wishes of the patient inferred by the family, and situations of the medical treatment and care.

<Anticipating the worsening of the disease conditions of the patient>

"I watched my mother getting weaker, with pleural effusions accumulated due to symptoms caused by the anticancer drugs that are no longer effective. She often undergoes treatment to eliminate these pleural effusions. $(Q F)$ "

$<$ Wishes of the family about how the patient should die>

"We rub the body (of my husband) I cannot really do any such thing, but I think, it is OK if my husband does what he wishes as much as he is able to, for emotional reasons. By doing so, I hope he can die without feeling anguished. $(B F)^{\prime \prime}$ 
<Inferring the way to die preferred by the patient>

"I don't know about what happens if the condition progresses a bit more, but at this stage he can stay at home without any inconvenience. I do not think he needs to be hospitalized yet. I suppose he wants to stay at home as long as the painkillers alleviate his pain. Maybe it is so. (KF)"

$<$ Determining the response when disease conditions become worse $>$

"Yes, if she is in the hospital, medical staff administers painkillers to her when she says she is in pain. When she says some part of her is in pain, she can have painkillers. I heard, a little while ago, there are some drugs that make her loose feeling completely. If such drugs are available, she will feel better because there is no pain, just no pain. (NF)"

$<$ Determining the place where both the patient and the family feels at ease>

"It may be better for the family as well, if the patient goes to a special place, like a hospice. Maybe, it sounds odd, but if she feels comfortable and becomes mentally stable, I think she should stay at a hospice. (PF)"

D) "Respecting the patient's intention as far as possible"

"Respecting the patient's intention as far as possible" means for the efforts of the family to try to obtain the patient consent to understand that the family cannot fulfill all the hopes of the patient, by explaining the limits of the care the family can provide although the family wishes to fulfill the hopes of the patient.

$<$ Respecting the intentions of the patient $>$

"If my father has something that he hopes for after all, I would like to make an effort for him to realize his wish. (OF)."

$<$ Establishing the limits of family care>

"There is a staircase in the house, and my husband cannot go up the stairs by himself. So, I think it becomes impossible for me. There are home visit services, but if we need the help at night, I think it will put the nurse to trouble. If I take care of him, I think both (my husband and I) may fall down, and it will cause my children a great deal of trouble. So I think it would be better for my husband to be taken care of at the hospital (GF)."

$<$ Gaining the understanding of the patient that a wish could not be realized $>$

"But... I think my husband really wants to stay home. I think so. But if his condition gets worse, I cannot do anything (I cannot respond). So, I said, "Please go to the hospital when his condition gets worse. $(B F)$ "

E) "Inferencing about the support desired by the patient"

"Inferencing about the support desired by the patient" means to determine what kind of support the patient is requesting in decision making about the place for death by inferring the need based on the reaction of the patient.

<Determining the decision-making competence of the patient>

"Before becoming hospitalized this time he was not terribly forgetful, and was still talking more rationally. Now I do not let him talk. Anyway, he does not say her opinion. (He) remains silent and just listens to me when (I) ask him "Don't 
you think this place is good enough?" (JF)"

<Inferring the patient preferred way of deciding>

"In my case, I want to do that (to make my wife's wish come true). But, Dad, she says, she may want me to look for places and decide on one. (AF)"

F) "Information from the medical staff"

"Information from the medical staff" means to be given explanations by the medical staff pertaining to the prospects for patients, choices, and characteristics of places of death, medical care, and services available at home. [Information from the medical staff] is a factor promoting [realizing the wish of patients in the terminal condition for the way for dying].

<Explanation from the physicians about the life expectancy>

"It was in May when I heard from the doctor about the life expectancy. He said, it had actually been until March (that the patient could survive). In such a situation, it would be easier for me to understand it (easier to accept the death of the patient). I do not mean I gave up easily, but what should I say..., all I could do was to be surprised. (OF)"

$<$ Information from the medical staff about the place for death for the patients>

"( Thinking that the hospice costs a lot), at first my mother and I did not think of staying at a hospice. But when I went to the counselor's office, the counselor said, "It is the same as the usual (general ward)." So, I said, "Is it true?" (DF)"

$<$ Suggestions for options from medical staff for a suitable place for patients to select>

"The doctor asked me, "Do you want to go home or to a hospice (in our hospita)? Which do you prefer? (FF)"

\section{Discussion}

\section{1. [Carefully Choosing the Final Place for Self-Fulfillment] in Relation to the Decision Making about the Place of Death of Elderly Patients with Advanced Cancer}

It has been reported that $70 \%-80 \%$ of patients with advanced cancer do not realize the cancer as incurable by chemotherapies [19], and that terminally-ill cancer patients have difficulty accepting a poor prognosis for the cancer [20]. When the patients of the current study (participating patients) [carefully choosing the final place for self-fulfillment], it was triggered by the "notion of an unavoidable death" after "accepting the discontinuation of anticancer treatment". This suggests that it is important to change the idea of the patient from one of staying alive with anticancer treatment to how they may spend the remaining days of life so that the patients will be able to investigate about the place for self-fulfillment during this final stage of life. This change becomes possible by <understanding the own disease condition that the remaining life will not be long $>$ and <reasoning to recognize death $>$ illustrated by the statement "I have worked hard enough. So I think it would be acceptable for me." expressing satis- 
faction with the lived life. As a previous study reports that elderly people feel death is close in relation to their life expectancy, and that they are searching for the meaning of their lives so far [21], the participating patients were able to realize satisfaction with their life and prepare for an inescapable death looking back on their life and reasoning that death is coming. It is also reported that it is easier for medical staff to find out the intention of patients and for the patients to acknowledge that they are dying in straightforward situations, where from the start there is the opportunity for medical staff and patients to discuss the place of death [22]. This indicates that it is important for patients to understand that there is no effective anticancer treatment and that their days are numbered making it a clear option that patients should choose a final place for self-fulfillment carefully.

For [carefully choosing the final place for self-fulfillment], complex considerations about the place of death are important, and it is especially important for patients to make the prospect of a worsening of their disease condition understood. As a previous study points out that the most important matter is for cancer patients to imagine, something that will happen in their future, and to think about what they want to do in thinking ahead about the disease conditions [23], medical staff needs to assist patients to become aware of worsening disease conditions. Most Japanese hope to be able to finish life without pain [24]. Cancer patients in the terminal stage wish to be cared for at a place where they will have medical care attending to symptom control as the place where they wish to die [25] [26] [27]. It can be inferred that the participating patients here also hoped to finish their lives without pain, tried to decide on a place of death where they would be able to cope with pain symptoms, and evaluated whether they could expect to lead life as desired at the place they chose. Cancer patients in the terminal stage hope that their dignity will be respected at the time of death [25] [28] [29], and that they can spend time as they like until then [30] [31]. It can be inferred that also the participating patients here were determining a place where they can expect to lead life as desired with dignity until the end.

Further, when the participating patients were [carefully choosing the final place for self-fulfillment], trying to embody the wishes for a way of life without difficulty was important. The wishes of the patients and the burden on their families were in conflict as illustrated by the statements "I hope I will be able do something at home, such as drawing" and "I do not want to show my suffering condition (to my family)." However, it was found that the participating patients embodied the wishes for a way of life without difficulty by considering the burden on the family, "If everyone becomes burdened, I would rather like to be hospitalized or look for a place at another facility..." Cancer patients consider the family burden in deciding on the place of death [12] [26] [29] [31], and especially when the cancer patients in the terminal stage are women, they try to maintain the role as caregivers by trying to keep their adult children from feeling any distress arising from caregiving, despite the serious disease [32]. These sug- 
gest that the participating patients were thinking about a place of death where children and spouses would not be burdened by their caring for the patients. It is reported that in Japan, the self-determination of the elderly is influenced by a culture that values harmony, a culture of overly-familiar interactions, and familyism through Confucianism, and that elderly people place importance on reconciling their conflicts by valuing family relationships in deciding the place for medical treatment and care [33]. These suggest that the participating patients could harbor ambivalent feelings by suppressing their desire and choosing the place of death in consideration of the burden of the family, as illustrated by the statement "I told my daughter (it is in my daughter's house) that I want to die there. But my daughter asked me what to do if my condition suddenly changes (as she was worried, and I chose the hospital)" in <inclusion of family opinions> as "preferences in the way of deciding the place of death". As a previous study points out that the QOL of patients will not improve if cancer patients remain in conflict [33], the matter of whether the desire of patients is reflected in the decision about the place of death is an important point.

\subsection{Characteristics of [Realizing the Wish of Patients in the Terminal Condition for the Way for Dying] in Relation to Their Families}

It is reported that family members play an important role in decision making in the treatment of cancer patients in the terminal stage, that they strongly hope for anticancer treatments [34], and that family members have difficulty accepting a poor prognosis for the sickness [20]. When the family members in the current study (participating families) made an effort to [realize the wish of patients in the terminal condition for the way for dying], "consent to the lack of anticancer treatment" and "preparation for the death of the patient" promoted the effort. For this reason, it is important for the participating families to accept the death of patients in the effort to realize the wish of patients for the way of dying. This acceptance was promoted by a clear explanation from physicians about the disease condition. In Japan physicians tend to tell the life expectancy to the family of patients first [35], and the family bothers greatly about whether they should be telling the life expectancy to the patient, and in effect suffer from this mental burden [36]. The participating families may have felt sadness in the process of preparing for the death of the patients, and have been under grave mental stress. For this reason, it is important for medical staff to assist the family to accept the discontinuation of anticancer treatment and the death of the patient, and also to alleviate the mental burden experienced in this process.

Examining the place of death from many viewpoints was important for the participating families to [realize the wish of patients in the terminal condition for the way for dying], and inferring the way to die preferred by the patient was specifically indispensable to respect the intention of the patient. Because of the Japanese cultural background, people view death as a taboo and avoid topics related to death [37]. It can be inferred that the participating families did not in- 
tentionally confirm the true intentions of the patients about topics related to the acceptance of death and preferences in the way for dying. This is because they considered the feelings of the dying patients, and perceived the thoughts and wishes of the patient from the daily conversation and discussion with physicians. A previous study has reported that all the patients interviewed there found it difficult to discuss the place of ongoing care in an advancing illness with their family on an emotional level [38]. However, it has also been reported that in the case of Japanese it is difficult to communicate the own intention to other persons accurately because the Japanese express many thoughts nonverbally, while respecting the unspoken inner thoughts and emotion [39]. Further, it has been reported that the intentions between the dying cancer patients and their families do not match [40] [41]. These suggest the importance of the verbal communication between the patients and their families to confirm the intentions of the patients to prevent a mismatch between the two parties, rather than just inferring the intentions.

The participating families clearly showed the limits of the care that they would be able to provide for the patients while respecting the intentions of the patients. According to a previous study, the burden arising from caregiving may increase the caregiver's vulnerability, and become a risk factor for fatigue and depression if the family overestimates their limits [42]. However, if the families underestimate the limits of care, they feel regret and self-responsibility for not fulfilling the wishes of the patients [29]. For this reason, it is necessary to clearly identify the limits of care the families can provide for the patients so that the families will provide the end-of-life care without regrets.

\subsection{Characteristics of the Relationship between Elderly Patients with Advanced Cancer and their Families in the Decision Making about the Place of Death}

The participating patients gained "understanding from the family for the decision making about the place of death" by carefully choosing the final place, while their families < gained the understanding of the patient that a wish could not be realized $>$ in the effort to realize the way to die preferred by the patient, and there were no mutual conflicts or negative feelings arising from the decision making. It has been reported that consensus building between the patients and families is important for the place of death of terminal cancer patients [26] [43] [44], and that the mutual understanding between the patients and families in the current study was the basis for consensus building of the place of death. These explain why there were no conflicts or negative feelings with these participants, suggesting that it is important for decision making about the place of death that both the patients and their family understand the intentions and wishes.

\subsection{Implications for Nursing to Support Elderly Patients with Advanced Cancer and Their Families in the Decision Making about the Place of Death}

In [carefully choosing the final place for self-fulfillment], it was important for 
the participating patients to change their idea focusing on how to spend the final days of life by understanding that their days are numbered and by reasoning in recognizing death. The participating families needed to accept the death of the patients to [realize the wish of patients in the terminal condition for the way of dying]. These suggest that nurse needs to explain medical information in an easy-to-understand manner, and assist the patients and their families to understand their disease conditions properly. It may be important for nurse to create opportunities where the patients and their families look back on their lives, and interact with them expressing satisfaction with life while considering their sorrow arising when accepting the death. Further, in the process of deciding the place of death, the participating patients and families made the outlook for the disease condition based on the explanations from the medical staff as information sources, and the future prospects were used as clues for their actions. It is said that cancer patients are likely to feel fear of death if they understand that death is close [45], and this suggests the importance of paying careful attention to their emotions to ensure that the patients and their families will not feel threatened by death when providing information.

The participating patients embodied the desire to live in their own way in consideration of the burden on their families, and this embodiment was influenced by the preference of the patients. This suggests that it is important for nurse to understand how the patients wish to decide the place of death and to support the patients and their families by ensuring the creation of opportunities where they can discuss how the patients try to realize their desires to live in their own way by considering the burden on their families. If the wishes for a way of life of the patients are reflected in the decision making about the place of death through this kind of support, the support may help patients realize their desired place of death and maintain their feelings of being in control, as well as it would maintain and improve QOL. As described above, it is necessary for families to clarify the limits of care that the families can provide for patients while respecting the intentions of the patients. This suggests the necessity for nurse to understand that the families wish to respect the intentions of the patients, as well as that they assist the families to clearly understand the limits of the care that the families can provide. Further, as a characteristic of the relationship between the participating patients and families, they gained an understanding of the intentions and wishes of each other by caring about the feelings of the other party. Since this is the basis for consensus building in the decision making about the place of death, it may be essential for nurse to provide opportunities where patients and their families can share and express their intentions and wishes with each other, and such efforts could play a role to help patients maintain and improve the QOL.

\section{Conclusions}

For elderly patients with advanced cancer, making the "tentative" decision about the place of death means choosing the final place for self-fulfillment carefully. 
The patients participating in the study here were embracing the wishes for a way of life without difficulty by conducting a comprehensive review of the place for the coming death and considering the burden on the family. The findings show the importance of reconciling the wishes of patients with the burden on families.

For families, getting involved in making a "tentative" decision about the place of death means to aim to realize the wishes of patients in the terminal condition for the way to die. The families were examining the place of death from different aspects, and trying to respect the patient intentions as far as possible by making clear the limits of family care. It was shown that it is necessary for families to balance the respect for the patient intentions and the homecare they are able to provide for the patient. In the relationship between the patients and families, mutually understanding the intentions and wishes of the other party is the basis for consensus building in decision making about the place of death, and this affects the decision making.

\section{Acknowledgements}

We would like to express our deep appreciation to the patients and their families taking part in the study for their cooperation in conducting this study. We would like to thank the physicians and nurses at medical institutions we recruited participants. We also thank Prof. Kazuko Matsugi, and Prof. Yasuhiro Tsuda all of Osaka Medical University for their helpful instruction throughout the study. We also wish to express our appreciation to Prof. Yasuhito Kinoshita of St. Luke's International University for many suggestions for the analysis. This research was supported by Grants of the Yuumi Memorial Foundation for Home Health Care.

\section{Conflicts of Interest}

The authors declare no conflicts of interest regarding the publication of this paper.

\section{References}

[1] The Editorial Board for Cancer Statistics in Japan (2018) Cancer Statistics. Foundation for Promotion of Cancer Research, Tokyo.

[2] Azuma, N. and Okuyama, A. (2019) National Cancer Registry 2017, Cancer Patients Registered in Designated Cancer Care Hospitals. National Cancer Center, Center for Cancer Control Information Services, Tokyo.

[3] Ministry of Health, Labour and Welfare (2019) Materials for the Working Group on Community Medicine Initiatives.

https://www.mhlw.go.jp/file/05-Shingikai-10801000-Iseikyoku-Soumuka/00002130 26.pdf

[4] Kinoshita, H., Maeda, I., Morita, T., Miyashita, M., Yamagishi, A., Shirahige, Y., et al. (2015) Place of Death and the Differences in Patient Quality of Death and Dying and Caregiver Burden. Journal of Clinical Oncology, 33, 357-363.

https://ascopubs.org/doi/10.1200/JCO.2014.55.7355

https://doi.org/10.1200/JCO.2014.55.7355 
[5] Shuto, M. (2018) Research on Matching the Factors Considered Important and Wishes Involved in Deciding Places for Medical Treatment, Treatment Place and Decision Making (Attachment 3), Learning from the J-HOPE 3 Study (Multicenter Bereaved Family Survey) (4th), Utilizing the Voice of the Bereaved Family in Clinical Practice. Japanese Journal of Cancer Care, 23, 55-57.

[6] Seow, H., Barbera, L., Sutradhar, R., Howell, D., Dudgeon, D., Atzema, C., et al. (2011) Trajectory of Performance Status and Symptom Scores for Patients with Cancer during the Last Six Months of Life. Journal of Clinical Oncology, 29, 1151-1158. https://ascopubs.org/doi/10.1200/JCO.2010.30.7173 https://doi.org/10.1200/JCO.2010.30.7173

[7] Silveira, M.J., Kim, S.Y. and Langa, K.M. (2010) Advance Directives and Outcomes of Surrogate Decision Making before Death. The New England Journal of Medicine, 62, 1211-1218. https://www.nejm.org/doi/full/10.1056/NEJMsa0907901 https://doi.org/10.1056/NEJMsa0907901

[8] Hirota, S., Masuda, S. and Sakagami, T. (2002) The World of Risk Seen by Psychology-Introduction to Behavioral Decision Making. Keio University Press, Tokyo.

[9] Bell, C.L., Somogyi-Zalud, E., Masaki, K.H., Bell, C.L., Somogyi-Zalud, E. and Masaki, K.H. (2010) Factors Associated with Congruence between Preferred and Actual Place of Death. Journal of Pain \& Symptom Management, 39, 591-604. https://doi.org/10.1016/j.jpainsymman.2009.07.007

[10] Shimizu, T. and Aida, K. (2017) Introduction to Death and Life Studies for Medicine and Nursing. University of Tokyo Press, Tokyo.

[11] Nakamura, S., Kuzuya, M., Funaki, Y., Matsui, W. and Ishiguro, N. (2010) Factors Influencing Death at Home in Terminally Ill Cancer Patients. Geriatrics \& Gerontology International, 10, 154-160. https://doi.org/10.1111/j.1447-0594.2009.00570.x

[12] Luijkx, K.G. and Schols, J.M. (2011) Perceptions of Terminally Ill Patients and Family Members Regarding Home and Hospice as Places of Care at the End of Life. European Journal of Cancer Care, 20, 577-584. https://doi.org/10.1111/j.1365-2354.2010.01228.x

[13] Yanagihara, K. (2009) Factors in the Process and Structure of the "Will Determination" by Families of Cancer Patients: Focusing on the Social Work at the "Gear Change" Stage and Terminal Stage. Bulletin of the Japan Lutheran College and Theological Seminary, 42, 77-96.

[14] Gomes, B. and Higginson, I.J. (2006) Factors Influencing Death at Home in Terminally Ill Patients with Cancer: Systematic Review. British Medical Journal (International Edition), 332, 515-518. https://doi.org/10.1136/bmj.38740.614954.55

[15] Suzuki, K., Hayashi, N., Fujita, S., Ogasa, M., Kabasawa, M. and Fukawa, A. (2017) Research Priorities of Oncology Nursing in Japan: The Website Survey by Member of Japanese Society of Cancer Nursing in 2016. Journal of Japanese Society of Cancer Nursing, 31, 57-65.

[16] Minamiguchi, Y. (2020) Decision-Making about the Place of Death for Cancer Patients: A Concept Analysis. Asia-Pacific Journal of Oncology Nursing, 7, 103-112. https://doi.org/10.4103/apjon.apjon_38_19

[17] Kinohsita, Y. (2003) Practice of Grounded Theory Approach: Invitation to Qualitative Research, Kobundou, Tokyo.

[18] Shenton, A.K. (2004) Strategies for Ensuring Trustworthiness in Qualitative Research Projects. Education for Information, 22, 63-75. https://doi.org/10.3233/EFI-2004-22201

[19] Weeks, J.C., Catalano, P.J., Cronin, A., Finkelman, M.D., Mack, J.W., Keating, N.L., 
et al. (2012) Patients' Expectations about Effects of Chemotherapy for Advanced Cancer. New England Journal of Medicine, 367, 1616-1625. https://doi.org/10.1056/NEJMoa1204410

[20] You, J.J., Downar, J., Fowler, R.A., Lamontagne, F., Ma, I.W.Y., Jayaraman, D., et al. (2015) Barriers to Goals of Care Discussions with Seriously Ill Hospitalized Patients and Their Families: A Multicenter Survey of Clinicians. JAMA Internal Medicine, 175, 549-556. https://doi.org/10.1001/jamainternmed.2014.7732

[21] Nakagi, S. and Tada, T. (2013) Issues Surrounding Life and Death among Japanese Elderly. Bulletin of Shikoku University, 41, 1-10.

[22] Munday, D., Petrova, M. and Dale, J. (2009) Exploring Preferences for Place of Death with Terminally Ill Patients: Qualitative Study of Experiences of General Practitioners and Community Nurses in England. BMJ, 339, b2391. https://doi.org/10.1136/bmj.b2391

[23] Kondo, M. (2017) To Support the Way of Life the Person Prefers-Practices in Advanced Care Planning-Process, Contents, and Support of ACP. Japanese Journal of Cancer Care, 22, 671-674.

[24] Miyashita, M., Sanjo, M., Morita, T., Hirai, K. and Uchitomi, Y. (2007) Good Death in Cancer Care: A Nationwide Quantitative Study. Annals of Oncology, 18, 10901097. https://doi.org/10.1093/annonc/mdm068

[25] Chapple, A., Evans, J., McPherson, A. and Payne, S. (2011) Patients with Pancreatic Cancer and Relatives Talk about Preferred Place of Death and What Influenced Their Preferences: A Qualitative Study. BMJ Supportive \& Palliative Care, 1, 291295. https://doi.org/10.1136/bmjspcare-2011-000091

[26] O’Sullivan, E.M. and Higginson, I.J. (2016) "I'll Continue as Long as I Can, and Die When I Can't Help It": A Qualitative Exploration of the Views of End-of-Life Care by Those Affected by Head and Neck Cancer (HNC). BMJ Supportive \& Palliative Care, 6, 43-51. https://doi.org/10.1136/bmjspcare-2014-000664

[27] Waller, A., Sanson-Fisher, R., Zdenkowski, N., Douglas, C., Hall, A. and Walsh, J. (2018) The Right Place at the Right Time: Medical Oncology Outpatients' Perceptions of Location of End-of-Life Care. Journal of the National Comprehensive Cancer Network, 16, 35-41. https://doi.org/10.6004/jnccn.2017.7025

[28] Choi, J.E., Miyashita, M., Hirai, K., Sato, K., Morita, T., Tsuneto, S., et al. (2012) Making the Decision for Home Hospice: Perspectives of Bereaved Japanese Families Who Had Loved Ones in Home Hospice. Japanese Journal of Clinical Oncology, 42, 498-505. https://doi.org/10.1093/jico/hys036

[29] Thomas, C., Morris, S. and Clark, D. (2004) Place of Death: Preferences among Cancer Patients and Their Carers. Social Science \& Medicine, 58, 2431-2444. https://doi.org/10.1016/j.socscimed.2003.09.005

[30] Loh, A.Z., Tan, J.S., Jinxuan, T., Lyn, T.Y., Krishna, L.K. and Goh, C.R. (2016) Place of Care at End of Life: What Factors Are Associated with Patients' and Their Family Members' Preferences? American Journal of Hospice \& Palliative Medicine, 33, 669-677. https://doi.org/10.1177/1049909115583045

[31] Sakai, K., Tsukahara, C., Iwaki, N. and Makino, C. (2011) Factors Influencing Advanced Cancer Patient and Their Family Decision-Making about Treatment Place. Ishikawa Journal of Nursing, 8, 41-50.

[32] Murray, M.A., O’Connor, A.M., Fiset, V. and Viola, R. (2003) Women's Decision-Making Needs Regarding Place of Care at End of Life. Journal of Palliative Care, 19, 176-184. https://doi.org/10.1177/082585970301900305

[33] Sasaki, Y. and Yamaguchi, Y. (2010) Nursing Assistance to Support Self-Determi- 
nation of the Elderly through the Relationship between Japanese Culture and Family. Hospice and Home Care, 18, 2-8.

[34] Laryionava, K., Pfeil, T.A., Dietrich, M., Reiter-Theil, S., Hiddemann, W. and Winkler, E.C. (2018) The Second Patient? Family Members of Cancer Patients and Their Role in End-of-Life Decision Making. BMC Palliative Care, 17, 29. https://bmcpalliatcare.biomedcentral.com/articles/10.1186/s12904-018-0288-2 https://doi.org/10.1186/s12904-018-0288-2

[35] Gabbay, B.B., Matsumura, S., Etzioni, S., Asch, S.M., Rosenfeld, K.E., Shiojiri, T., et al. (2005) Negotiating End-of-Life Decision Making: A Comparison of Japanese and U.S. Residents' Approaches. Academic Medicine, 80, 617-621. https://doi.org/10.1097/00001888-200507000-00003

[36] Shimizu, M. and Yanagihara, K. (2018) Research on Difficulties in Decision Making Experienced by Families of Cancer Patients, Difficulties in Decision Making (Attachment 24), Learning from the J-HOPE 3 Study (Multicenter Bereaved Family Survey) (6th), Utilizing the Voice of the Bereaved Family in Clinical Practice. Japanese Journal of Cancer Care, 23, 437-440.

[37] Sakamoto, K. (2013) Death-Life View and Death Acceptance of Terminally Ill Patients in Japan. Ochanomizu University Studies in Arts and Culture, 9, 59-70.

[38] McCall, K. and Rice, A.M. (2005) What Influences Decisions around the Place of Care for Terminally Ill Cancer Patients? International Journal of Palliative Nursing, 11, 541-547. https://doi.org/10.12968/ijpn.2005.11.10.19983

[39] Sato, N. (1995) Cross-Cultural Studies. Shogakusya, Tokyo.

[40] Fukui, S., Morita, T. and Yoshiuchi, K. (2017) Development of a Clinical Tool to Predict Home Death of a Discharged Cancer Patient in Japan: A Case-Control Study. International Journal of Behavioral Medicine, 24, 584-592. https://doi.org/10.1007/s12529-016-9619-y

[41] Ikezaki, S. and Ikegami, N. (2011) Predictors of Dying at Home for Patients Receiving Nursing Services in Japan: A Retrospective Study Comparing Cancer and Non-Cancer Deaths. BMC Palliative Care, 10, 3. https://doi.org/10.1186/1472-684X-10-3

[42] Proot, I.M., Abu-Saad, H.H., Crebolder, H.F., Goldsteen, M., Luker, K.A. and Widdershoven, G.A. (2003) Vulnerability of Family Caregivers in Terminal Palliative Care at Home; Balancing between Burden and Capacity. Scandinavian Journal of Caring Sciences, 17, 113-121. https://doi.org/10.1046/j.1471-6712.2003.00220.x

[43] Alonso-Babarro, A., Bruera, E., Varela-Cerdeira, M., Boya-Cristia, M.J., Madero, R., Torres-Vigil, I., et al. (2011) Can This Patient be Discharged Home? Factors Associated with At-Home Death among Patients with Cancer. Journal of Clinical Oncology, 29, 1159-1167. https://doi.org/10.1200/JCO.2010.31.6752

[44] Ministry of Health, Labour and Welfare (2018) Guidelines on Decision-Making Processes for Medical Care at the Final Stage of Life: A Study Group on How to Disseminate Medical Knowledge and Understanding at the Final Stage of Life. https://www.mhlw.go.jp/stf/houdou/0000197665.html

[45] Back, A.L., Arnold, R.M. and Quill, T.E. (2003) Hope for the Best, and Prepare for the Worst. Annals of Internal Medicine, 138, 439-443.

https://annals.org/aim/article-abstract/716134/hope-best-prepare-worst https://doi.org/10.7326/0003-4819-138-5-200303040-00028 